\title{
nature
}

\section{A time for scientific diplomacy}

Both India and Pakistan have much to gain from closer collaboration between their scientific communities. Such collaboration must not be allowed to remain a casualty of tensions between the two.

T he decisions by India and Pakistan to detonate nuclear devices will have few - if any — direct consequences for the relations between ordinary citizens of both countries. They won't, for example, diminish the passion Pakistanis have for Indian cinema, nor the fondness that Indians hold for Pakistani television soap operas. India won't stop Muslims from Pakistan flocking to the shrines of revered Sufi saints. And Pakistan won't stop Sikhs from India crossing the border to visit their second-holiest temple.

But the tests will almost certainly hamper communication between one group of Indians and Pakistanis who would like the chance to talk more: the scientists of both countries. The irony for those who gave their countries nuclear weapons status is that they face increased isolation, not only from the West, but also from each other. Science is perhaps one of the few vehicles that could help raise both the quality of life and levels of trust between these two quarrelsome neighbours. But at present, official, bilateral scientific cooperation does not exist.

Scientists from both countries are not totally isolated from one another. They meet at international venues, such as the Abdus Salam Centre for Theoretical Physics in Trieste, Italy, and at United Nations environment conventions, where both countries form part of the Group of 77 developing states. Pakistan's scientists can, in theory, travel to New Delhi to visit the International Centre for Genetic Engineering and Biotechnology. Indian scientists, similarly, can travel to Islamabad to visit the headquarters of the intergovernmental Commission on Science for Sustainable Development for the South. Some maintain good personal relations with cross-border colleagues.

But in practice, contact is rare. Scientific collaboration may have helped thaw the Cold War in the West, but it has become one of the casualties of the continued tense relations between India and Pakistan. Politicians from both sides view science as a key element of each country's defence and security, and consider scientific cooperation - no matter how innocuous - as close to giving away state secrets. If pressed, they tend to take the view that enhanced scientific collaboration will follow progress on outstanding political issues, not vice versa.

This is unfortunate, as scientific collaboration can - as the West has shown - help to ease political tensions. It is also wrong, as such collaboration could bring urgent, practical benefits to both countries. Indeed, science could be harnessed to help India and Pakistan tackle a range of common problems. These include diseases such as malaria and tuberculosis; agricultural issues such as developing salt tolerance in crops; and environmental issues such as air pollution, as India and Pakistan have similar types of road transport.

There is, in fact, much evidence that scientists from both countries would like to collaborate. But they need both permission and support from their politicians, which has so far been lacking. This support in turn needs courage, diplomacy, an element of 'lateral thinking', and an enlightened view of India-Pakistan relations.

Such thinking is not unknown and once came from an unlikely source. In 1987, Pakistan's military president General Zia ul Haq tried to defuse rising tensions by travelling across the border to make an unscheduled appearance at an India-Pakistan cricket match. The incident was coined 'cricket diplomacy'. And it worked. Pakistan's present prime minister, Nawaz Sharif, a Zia protégé, could take a cue from his mentor, and engage in a bit of 'scientific diplomacy'. What does he have to lose?

\section{When moderation turns to greed}

The NIH must be ready to take firm action to protect access to the tools that are essential to a researcher's work.

$\Gamma$ ew issues are as frustrating to the contemporary researcher, particularly in the life sciences, as the time and effort spent negotiating the terms on which he or she can gain access to the research tools required to do an efficient job. In a less complex - perhaps slightly mythical - era, biological samples were exchanged freely between laboratories, equipment manufacturers were content merely if their products carried out specified tasks effectively, and experimental results were disseminated widely and rapidly.

In today's world, as a report compiled by a working group set up by the National Institutes of Health (NIH) makes clear (see page 505), the demands of licensing agreements and the enforced need to respect the intellectual property of others is reaching critical dimensions. Samples can be jealously guarded, manufacturers can exploit the ownership of unique technologies, the terms of collaboration can be stringent, and publication can be delayed on demand. The working party's conclusion is stark: "We believe that current trends pose a serious threat to the best interests of the biomedical research and development community as a whole."

The problem is when common sense and moderation give way to greed. It is one thing, for example, to expect a reasonable return from a discovery that will undoubtedly bring profit to others; it is another to exploit the virtual monopoly position which the law, in the hands of an aggressive and imaginative patent attorney, can potentially allow one researcher to exercise over another. The fault does not always lie in the explicitly profit-motivated private sector. The NIH working group says it found those in industry who had been taken aback by the price of cooperation being demanded by some university researchers.

Given the diversity of situations in which tensions can arise, and the widely varying practices between different parts of the scientific community, there are no easy solutions - certainly none that could be enshrined in compact legislation. The NIH, also aware of the limited range of its responsibilities, is right to talk more in terms of building a consensus around broad guidelines. But it must not shirk from making unpopular judgements, for example by exercising its 'march-in' rights, where the long-term interests of biomedical research conflict with the short-term avarice of individuals. Science is one domain where belief in Adam Smith's 'invisible hand' can create as many problems as it solves. 